OPEN ACCESS

Edited by:

Xinhua Shu,

Glasgow Caledonian University,

United Kingdom

Reviewed by:

Rosario Gulino,

University of Catania, Italy

*Correspondence:

Joanna M. Williams

joanna.williams@otago.ac.nz

Specialty section: This article was submitted to

Integrative Physiology,

a section of the journal

Frontiers in Physiology

Received: 01 December 2021

Accepted: 27 December 2021

Published: 10 February 2022

Citation:

Chu AJ and Williams JM (2022) Astrocytic MicroRNA in Ageing,

Inflammation, and Neurodegenerative

Disease. Front. Physiol. 12:826697.

doi: 10.3389/fphys.2021.826697

\section{Astrocytic MicroRNA in Ageing, Inflammation, and Neurodegenerative Disease}

\author{
Aimee J. Chu and Joanna M. Williams* \\ Department of Anatomy, Brain Health Research Centre, University of Otago, Dunedin, New Zealand
}

Astrocytes actively regulate numerous cell types both within and outside of the central nervous system in health and disease. Indeed, astrocyte morphology, gene expression and function, alongside the content of astrocyte-derived extracellular vesicles (ADEVs), is significantly altered by ageing, inflammatory processes and in neurodegenerative diseases, such as Alzheimer's disease, Parkinson's disease and amyotrophic lateral sclerosis. Here, we review the relevant emerging literature focussed on perturbation in expression of microRNA (miRNA), small non-coding RNAs that potently regulate gene expression. Synthesis of this literature shows that ageing-related processes, neurodegenerative disease-associated mutations or peptides and cytokines induce dysregulated expression of miRNA in astrocytes and in some cases can lead to selective incorporation of miRNA into ADEVs. Analysis of the miRNA targets shows that the resulting downstream consequences of alterations to levels of miRNA include release of cytokines, chronic activation of the immune response, increased apoptosis, and compromised cellular functioning of both astrocytes and ADEV-ingesting cells. We conclude that perturbation of these functions likely exacerbates mechanisms leading to neuropathology and ultimately contributes to the cognitive or motor symptoms of neurodegenerative diseases. This field requires comprehensive miRNA expression profiling of both astrocytes and ADEVs to fully understand the effect of perturbed astrocytic miRNA expression in ageing and neurodegenerative disease.

Keywords: astrocytes, microRNA, Alzheimer's disease, Parkinson's disease, amyotrophic lateral sclerosis, ageing, inflammation, neurodegeneration

\section{INTRODUCTION}

Astrocytes are highly ramified glial cells found throughout the central nervous system (CNS). Originally thought to provide little more than structural support for neurons, it is now evident that astrocytes actively regulate numerous functions and cell types in both the healthy and diseased brain. Astrocytes are a fundamental component of both the tripartite synapse and blood-brain barrier (BBB). The intimate proximity of astrocytes to neurons and capillary wallforming endothelial cells allows astrocytes to modulate and optimise the synaptic and wider CNS 
environment for current and future activity. Astrocytes regulate blood flow, distribute nutrients to nearby neurons, take up and recycle excess neurotransmitters and spent metabolites and release gliotransmitters, synaptogenic and neurotrophic factors and neurotransmitter precursors (Sofroniew and Vinters, 2010; Baldwin and Eroglu, 2017). Furthermore, significant crosstalk between astrocytes, microglia, other CNS cell types and CNSnon-resident cells is mediated by a variety of signalling molecules including growth factors and cytokines. This enables astrocytes, especially in response to CNS injury, to actively regulate the cellular responses and transcriptional profiles of other cell types while being regulated themselves in a similar manner (Linnerbauer et al., 2020; Matejuk and Ransohoff, 2020).

Intercellular communication is also facilitated by the release of astrocyte-derived extracellular vesicles (ADEVs). ADEVs, including exosomes and microvesicles, are vesicles of 30$1,000 \mathrm{~nm}$ containing proteins and functional genetic material (Valadi et al., 2007) encased by a lipid bilayer (Zhao et al., 2021). ADEVs can be internalised by neurons (Ibáñez et al., 2019; Xu et al., 2019), microglia (Neckles et al., 2019; Liao et al., 2020), oligodendrocytes (Willis et al., 2020), endothelial cells (Kriaučiūnaitè et al., 2021), and other astrocytes (Ipas et al., 2015), while ADEV transfer across the BBB enables astrocytes to influence cells beyond the CNS (Cai et al., 2017; Dickens et al., 2017). Differences between the cargo of ADEVs and the originating astrocytes (Ipas et al., 2015; Jovičić and Gitler, 2017) point to the existence of preferential packaging mechanisms (Groot and Lee, 2020), suggesting that curation of ADEV content is an important mechanism by which astrocytes communicate with other cells.

Following acute and chronic CNS injury, astrocytes undergo morphological, molecular and functional changes that are collectively termed reactive astrogliosis (Escartin et al., 2021). Whether these changes, such as the formation of a glial scar, are beneficial or detrimental depends on the severity and nature of the insult (Sofroniew and Vinters, 2010). Loss of normal astrocyte functions alongside gain of toxic functions can further exacerbate pathological processes (Sofroniew and Vinters, 2010). Neurodegenerative diseases, including Alzheimer's disease (AD), Parkinson's disease (PD) and amyotrophic lateral sclerosis (ALS), are characterised by CNS inflammation and deteriorating cognitive and/or motor function. These symptoms arise from the steady and irreversible degeneration of neurons in the brain or spinal cord, but the astrocytic contribution to the pathological processes underlying these chronic conditions is becoming increasingly recognised (Pekny et al., 2016). Dysregulated gene expression is a well-established feature of neurodegenerative disorders and normal ageing (Cooper-Knock et al., 2012). Recent work has highlighted the contribution of microRNA (miRNA), short non-coding RNAs that finetune gene expression by inhibiting protein translation, to neurodegenerative and ageing processes (Danka Mohammed et al., 2017; Shaik et al., 2018; Gagliardi et al., 2019; Goh et al., 2019). This includes a nascent literature evaluating the role of astrocyte-derived miRNA.

Here, we review accumulating evidence implicating disrupted miRNA expression in astrocytes and ADEVs in the pathophysiology of neurodegenerative diseases, highlighting downstream targets of the perturbed miRNA and the biological pathways affected. We build on recent reviews (Neal and Richardson, 2018; Bai et al., 2021) by considering alterations to astrocytic miRNA expression in ADEVs and that arising from ageing and inflammatory processes. It is important to note that studies utilising astrocytoma or glioblastoma cells to represent astrocytes were not included due to the well-documented differences in miRNA expression between primary astrocytes and cultures derived from astrocytoma cell lines (Lee et al., 2013; Zhou et al., 2017).

\section{MicroRNA FUNCTION AND REGULATION}

Gene silencing is initiated following the interaction of a seed sequence (nucleotides 2-8) at the $5^{\prime}$ end of a mature miRNA with a perfectly complementary sequence in the $3^{\prime}$-untranslated region of a target mRNA (Chipman and Pasquinelli, 2019). The subsequent displacement of translation initiation complexes from the mRNA or recruitment of mRNA-degrading protein complexes ultimately results in reduced expression of the target protein (Iwakawa and Tomari, 2015). As most mammalian miRNAs are only partially complementary to their targets beyond the seed sequence, one miRNA can regulate numerous compatible mRNAs. Furthermore, one mRNA can be targeted by multiple miRNAs. Fascinatingly, both mature miRNA and precursor miRNA have been identified within EVs (Chen et al., 2010). Thus, perturbed miRNA expression is likely to have numerous downstream consequences.

Complex biogenesis paired with numerous transcriptional and post-transcriptional regulatory mechanisms provides multiple opportunities to regulate miRNA expression. Access of RNA polymerase II or transcriptional regulators to the genes encoding miRNA can be facilitated or restricted by epigenetic modifications, such as DNA methylation or chromatin remodelling and the binding of transcription factors (TFs) to miRNA promotor regions (Morales et al., 2017), leading to altered amounts of miRNA transcripts within cells. Notably, all of these mechanisms have been associated with various neurodegenerative conditions (Kwon et al., 2016; Berson et al., 2018). Furthermore, miRNA can regulate their own expression via positive and negative feedback loops (Zuo et al., 2016; Inukai et al., 2018; Ferro et al., 2019).

\section{DYSREGULATION OF MicroRNA AND THEIR TARGET MRNA IN ASTROCYTES AND ASTROCYTE-DERIVED EXTRACELLULAR VESICLES IN NEURODEGENERATIVE DISEASES}

Increasing evidence suggests that dysregulation of astrocytic and ADEV-associated miRNA is a common feature of neurodegenerative disease. Table 1 summarises studies showing a direct link between ageing, inflammation, neurodegenerative diseases or disease-relevant stimuli and altered expression of 
TABLE 1 | Differentially expressed microRNA in astrocytes and astrocyte-derived extracellular vesicles in ageing, inflammation, and neurodegenerative disease.

\begin{tabular}{|c|c|c|c|c|c|c|c|}
\hline \multirow[t]{2}{*}{$\begin{array}{l}\text { Disease/ } \\
\text { condition }\end{array}$} & \multirow[t]{2}{*}{ miRNA } & \multicolumn{2}{|c|}{$\begin{array}{l}\text { Direction of change in treated or } \\
\text { diseased astrocytes or ADEVs (cf. } \\
\text { control) }\end{array}$} & \multirow[t]{2}{*}{ Type of study } & \multirow[t]{2}{*}{ Target genes } & \multirow[t]{2}{*}{ Treatment/model } & \multirow[t]{2}{*}{ Study } \\
\hline & & Astrocytes & ADEVs & & & & \\
\hline$A D$ & miR-146a-(5p) & $\uparrow$ & & Targeted: Northern blot & $\operatorname{IRAK} 1^{\mathrm{b}, \mathrm{d}}$ & $\begin{array}{c}5 \mu \mathrm{M} A \beta_{42}+10 \mathrm{ng} / \mathrm{mL} \mathrm{IL}-1 \beta \text {-treated HAG } \\
\text { cells }\end{array}$ & Cui et al., 2010 \\
\hline$A D$ & miR-155 & $\uparrow$ & & Targeted: RT-qPCR & Socs $1^{b}$ & $\begin{array}{c}A \beta_{42} \text { fibril }(30 \mu \mathrm{M}, 24 \mathrm{~h}) \text { treated primary } \\
\text { murine astrocytes }\end{array}$ & Guedes et al., 2014 \\
\hline$A D$ & miR-146a & $\uparrow$ & & $\begin{array}{c}\text { Targeted: Northern blot and } \\
\text { RT-qPCR }\end{array}$ & $\begin{array}{l}C F H^{\mathrm{b}, \mathrm{d}}, \text { IRAK } 1^{\mathrm{b}, \mathrm{d}} \\
\text { TSPAN } 12^{\mathrm{b}, \mathrm{d}}\end{array}$ & $\begin{array}{c}5 \mu \mathrm{MA} \beta_{42}+10 \mathrm{nM} \mathrm{TNF} \alpha(1 \text { week) treated } \\
\mathrm{HAG} \text { cells }\end{array}$ & Li et al., 2011 \\
\hline \multirow[t]{2}{*}{ Ageing } & $\begin{array}{l}\text { miR-16-(5p), miR-17-(5p), } \\
\quad \text { miR-140-(3p) }\end{array}$ & $\uparrow$ & & $\begin{array}{l}\text { Exploratory: MMChIP assay with } \\
\text { RT-qPCR validation }\end{array}$ & $\begin{array}{l}\text { Mapk } 3^{b}, \text { Ngfrb }^{b} \\
\left(\text { miR-206-3p), Tnf- } \alpha^{b}\right.\end{array}$ & $\begin{array}{l}\text { HO-1 overexpression in primary rodent } \\
\text { astrocytes }\end{array}$ & Lin et al., 2015 \\
\hline & $\begin{array}{l}\operatorname{miR}-29 c-(3 p), \operatorname{miR}-138-(5 p) \\
\text { miR-181a-(5p), miR-187-(3p), } \\
\quad \text { miR-206-(3p), miR-297 }\end{array}$ & $\downarrow$ & & & $\begin{array}{l}(\operatorname{miR}-181 a-5 p), \text { Sirt }{ }^{10} \\
\text { Slc17a7b (miR-138-5p) }\end{array}$ & & \\
\hline Ageing & miR-335-3p & $\uparrow$ & & Targeted: RT-qPCR & $\operatorname{Hmgcs}^{\mathrm{a}}{ }^{\mathrm{a}, \mathrm{d}}$, Sfrs $^{\mathrm{a}, \mathrm{d}}$ & $\begin{array}{l}\text { Young (7 DIV) cf. aged (35 DIV) primary } \\
\text { murine astrocytes }\end{array}$ & Raihan et al., 2018 \\
\hline ALS & miR-21-(5p), miR-146a-(5p) & $\downarrow$ & & Targeted: RT-qPCR & $\begin{array}{l}\operatorname{Irak} 7^{b}, \text { Traffb }^{b} \\
\text { (miR-146a-5p) }\end{array}$ & $\begin{array}{l}\text { Primary cortical astrocytes from mSOD1 } \\
\text { mice }\end{array}$ & Gomes et al., 2019 \\
\hline \multirow[t]{2}{*}{ ALS } & $\begin{array}{l}\text { miR-21-5p, miR-146a-5p } \\
\text { miR-155-5p }\end{array}$ & $\downarrow$ & $\downarrow$ & Targeted: RT-qPCR & No targets investigated & $\begin{array}{l}\text { Primary cortical astrocytes from mSOD1 } \\
\text { mice and secreted ADEVs }\end{array}$ & Gomes et al., 2020 \\
\hline & & $\uparrow$ & $\downarrow$ & & & $\begin{array}{l}\text { Primary spinal cord astrocytes from mSOD1 } \\
\text { mice and secreted ADEVs }\end{array}$ & \\
\hline ALS & $\begin{array}{c}\text { TaqMan }^{\mathrm{TM}} \text { Array Rodent microRNA } \\
\text { A + B Cards v3.0 }\end{array}$ & Not assessed & $\begin{array}{l}\text { No change } \\
\text { observed in any of } \\
\text { the } 752 \text { miRNA } \\
\text { investigated }\end{array}$ & Exploratory: TLDA RT-qPCR & No targets investigated & $\begin{array}{l}\text { ADEVs from primary mSOD1 murine } \\
\text { astrocytes }\end{array}$ & $\begin{array}{l}\text { Jovičić and Gitler, } \\
\qquad 2017\end{array}$ \\
\hline ALS & miR-494-3p & Not assessed & $\downarrow$ & $\begin{array}{l}\text { Exploratory: GeneChip array with } \\
\text { RT-qPCR validation }\end{array}$ & SEMA3A $A^{b}$ & $\begin{array}{l}\text { ADEVS from patient-derived iAstrocytes } \\
\text { (C9orf72 mutation) }\end{array}$ & Varcianna et al., 2019 \\
\hline Inflammation & $\begin{array}{l}\text { let-7f-(5p), miR-16-5p, } \\
\text { miR-100-(5p), miR-125a-5p, } \\
\text { miR-125b-5p }\end{array}$ & No change & $\uparrow$ & $\begin{array}{l}\text { Exploratory: } n \text { Counter with } \\
\text { RT-qPCR validation }\end{array}$ & $\begin{array}{l}\text { Ntrk3 }{ }^{\mathrm{a}, \mathrm{d}}, \mathrm{Bcl} 2^{\mathrm{a}, \mathrm{d}} \\
(\mathrm{miR}-125 \mathrm{a}-5 \mathrm{p} \text { and } \\
\text { miR-16-5p) }\end{array}$ & $\begin{array}{l}\text { IL-1 }(200 \mathrm{ng} / \mathrm{mL}, 2 \mathrm{~h}) \text { treated primary } \\
\text { rodent astrocytes and secreted ADEVs }\end{array}$ & Chaudhuri et al., 2018 \\
\hline Inflammation & $\begin{array}{l}\text { miR-16-5p, miR-107, } \\
\text { miR-125a-5p, miR-125b-5p, } \\
\text { miR-145-(5p) }\end{array}$ & No change & $\uparrow$ & $\begin{array}{l}\text { Exploratory: } n \text { Counter with } \\
\text { RT-qPCR validation }\end{array}$ & $\begin{array}{l}\text { Ntrk3 }{ }^{\mathrm{a}, \mathrm{d}}, \mathrm{Bcl} 2^{\mathrm{a}, \mathrm{d}} \\
(\mathrm{miR}-125 \mathrm{a}-5 \mathrm{p} \text { and } \\
\text { miR-16-5p) }\end{array}$ & $\begin{array}{l}\text { TNF } \alpha(200 \mathrm{ng} / \mathrm{mL}, 2 \mathrm{~h}) \text { treated primary } \\
\text { rodent astrocytes and secreted ADEVs }\end{array}$ & Chaudhuri et al., 2018 \\
\hline Inflammation & miR-30d-(5p), miR-141-3p & $\uparrow$ & $\uparrow$ & $\begin{array}{l}\text { Exploratory: TLDA RT-qPCR with } \\
\text { ddPCR validation }\end{array}$ & No targets investigated & $\begin{array}{l}\text { IL-1 } \beta(10 \mathrm{ng} / \mathrm{mL}, 24 \mathrm{~h}) \text { treated primary } \\
\text { human astrocytes and secreted ADEVs }\end{array}$ & Gayen et al., 2020 \\
\hline Inflammation & miR-146a & $\uparrow$ & & Targeted: RT-qPCR & IRAK $1^{\mathrm{b}, \mathrm{d}}$, TRAFG $^{\mathrm{b}}$ & $\begin{array}{c}\text { IL-1 } 1 \text { (10 ng/mL, } 24 \mathrm{~h}) \text { treated primary } \\
\text { human astrocytes }\end{array}$ & lyer et al., 2012 \\
\hline Inflammation & miR-23a, miR-146a, miR-155 & $\uparrow$ & & $\begin{array}{l}\text { Exploratory: TLDA RT-qPCR with } \\
\text { RT-qPCR validation }\end{array}$ & CD47a (miR-155) & $\begin{array}{c}\mathrm{IL}-1 \beta(0.05 \mu \mathrm{g} / \mathrm{mL}, 24 \mathrm{~h}) \text { or TNF } \alpha \\
(0.01 \mu \mathrm{g} / \mathrm{mL}, 24 \mathrm{~h}) \text { treated primary human } \\
\text { astrocytes }\end{array}$ & Junker et al., 2009 \\
\hline Inflammation & miR-155-5p & $\uparrow$ & & Targeted: RT-qPCR & No targets investigated & $\begin{array}{l}\text { IL-1 } 1 \text { (10 ng/mL, } 24 \mathrm{~h}) \text { treated primary } \\
\text { human astrocytes }\end{array}$ & Korotkov et al., 2018 \\
\hline Inflammation & miR-146a-5p & $\uparrow$ & & Targeted: RT-qPCR & Traf6a,d & $\begin{array}{l}\text { IL-1 } 1 \beta \text { or TNF } \alpha \text { (both } 10 \mathrm{ng} / \mathrm{mL}, 6-24 \mathrm{~h} \text { ) } \\
\text { treated primary murine astrocytes }\end{array}$ & Lu et al., 2015 \\
\hline Inflammation & miR-125b-(5p) & $\uparrow$ & & $\begin{array}{l}\text { Exploratory: Fluorescent miRNA } \\
\text { array panels with Northern blot } \\
\text { validation }\end{array}$ & $C D K N 2 A^{d}$ & $\begin{array}{c}\text { IL-6 }(10 \mu \mathrm{M}, 18 \text { and } 36 \mathrm{~h}) \text { treated normal } \\
\text { human astrocytes }\end{array}$ & Pogue et al., 2010 \\
\hline Inflammation & $\begin{array}{l}\text { miR-155-(5p), miR-155* } \\
\quad(\operatorname{miR}-155-3 p)\end{array}$ & $\uparrow$ & & $\begin{array}{c}\text { Exploratory: Illumina microarray with } \\
\text { RT-qPCR validation }\end{array}$ & $S O C S 1^{b, d}(\operatorname{miR}-155-5 p)$ & $\begin{array}{c}\text { IL-1 } 1 \beta \text { or TNF } \alpha \text { (both } 10 \mathrm{ng} / \mathrm{mL}, 24 \mathrm{~h} \text { ) treated } \\
\text { primary human astrocytes }\end{array}$ & $\begin{array}{l}\text { Tarassishin et al., } \\
2011\end{array}$ \\
\hline
\end{tabular}




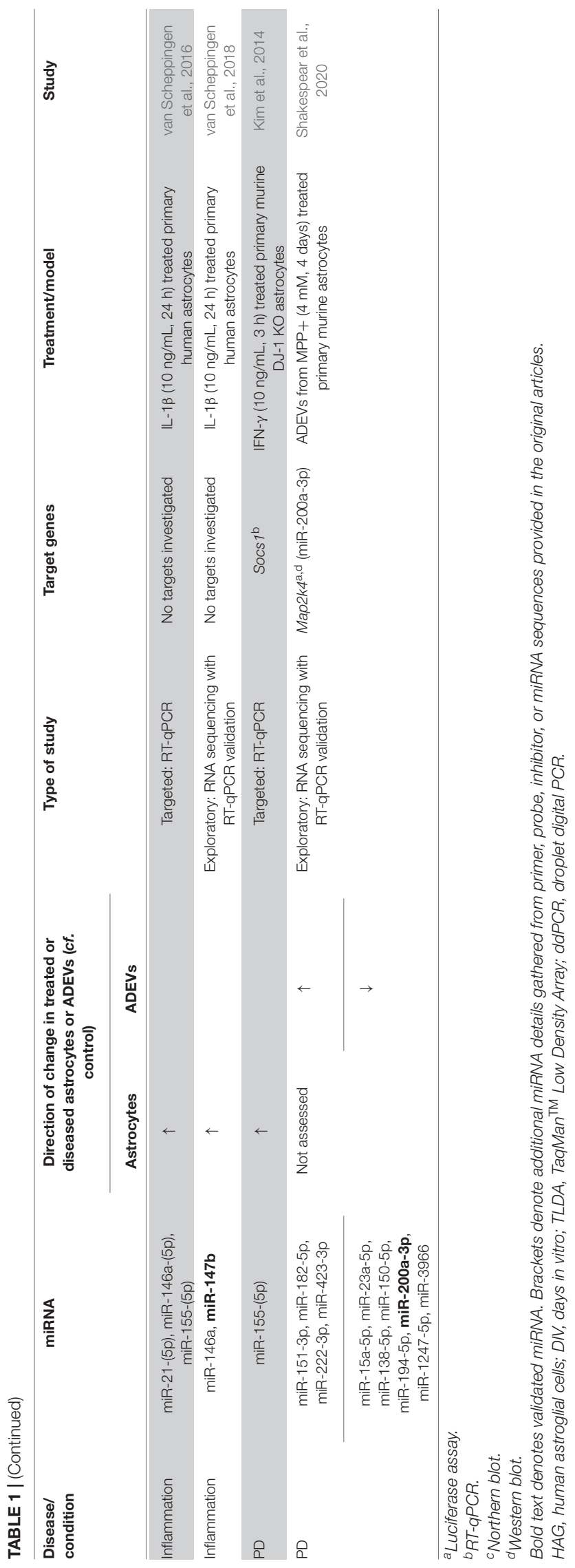

miRNA within astrocytes or ADEVs. Target genes are noted where investigated.

\section{Dysregulation of MicroRNA in Astrocytes in Normal Ageing}

Increasing age is an established risk factor for the development of most neurodegenerative conditions. Even normal ageing is often accompanied by reductions in cognitive function, underpinned by impaired synaptic communication, altered metabolism and mitochondrial dysfunction in ageing neurons (Hou et al., 2019; Temido-Ferreira et al., 2019). Furthermore, the mild inflammatory state of the ageing brain (Palmer and Ousman, 2018) is likely driven by non-neuronal cells. Notably, ageing is associated with morphological, molecular and functional changes in astrocytes (Palmer and Ousman, 2018; Willis et al., 2020). Furthermore, RNA-sequencing of astrocytes from aged wildtype mice reveals that ageing induces significant changes in gene expression (Boisvert et al., 2018; Habib et al., 2020). However, little is known about ageing-induced alterations to miRNA expression in astrocytes. Nevertheless, two in vitro studies have reported dysregulated astrocytic miRNA expression in response to models of non-pathological ageing.

One study modelling normal ageing by extended culture (35 days) of primary murine astrocytes observed significant elevation of miR-335-3p compared to younger (7 days) astrocytes (Raihan et al., 2018). A concomitant decrease in the expression of direct targets HMGCS1 and SFRS2 was also observed, alongside reduced astrocytic cholesterol levels. Delivery of astrocytederived cholesterol to neurons via lipoproteins is essential for synaptic formation and function (Pfrieger, 2003), and HMGCS1 and SFRS2 are critical components of the cholesterol production pathway. Notably, impaired cholesterol synthesis in astrocytes arising from overexpression of miR-335-3p led to a downregulation of the essential synaptic protein PSD95 in neurons, while reducing miR-335-3p levels in the hippocampus of aged mice raised PSD95 protein levels and cholesterol production and was associated with improved performance on learning and memory tasks (Raihan et al., 2018; Figure 1A).

Heme oxygenase-1 (HO-1) is an inducible enzyme involved in the heme catabolism pathway. HO-1 expression is positively correlated with increasing age in post mortem brain with no observable neuropathology (Hirose et al., 2003). Astrocytes overexpressing HO-1 had significantly higher levels of three miRNA, while six miRNA were downregulated (Lin et al., 2015; Table 1). Tumour necrosis factor-alpha $(\operatorname{Tnf}-\alpha)$, nerve growth factor receptor $(\mathrm{Ngfr})$, mitogen-activated protein kinase 3 (Mapk3), Sirtuin 1 (Sirt1), and Slc17a7, which encodes the glutamate transporter VGLUT1, are known targets of the downregulated miRNA and were significantly upregulated in HO-1-overexpressing astrocytes (Lin et al., 2015). This suggests that multiple processes related to both astrocytic and neuronal physiology may be dysregulated as a result of age-related increases in HO-1 expression and accompanying miRNA dysregulation. Interestingly, upregulation of HO1 expression, predominantly in astrocytes, has also been observed in neurodegenerative conditions, such as $\mathrm{AD}$ and $\mathrm{PD}$ 


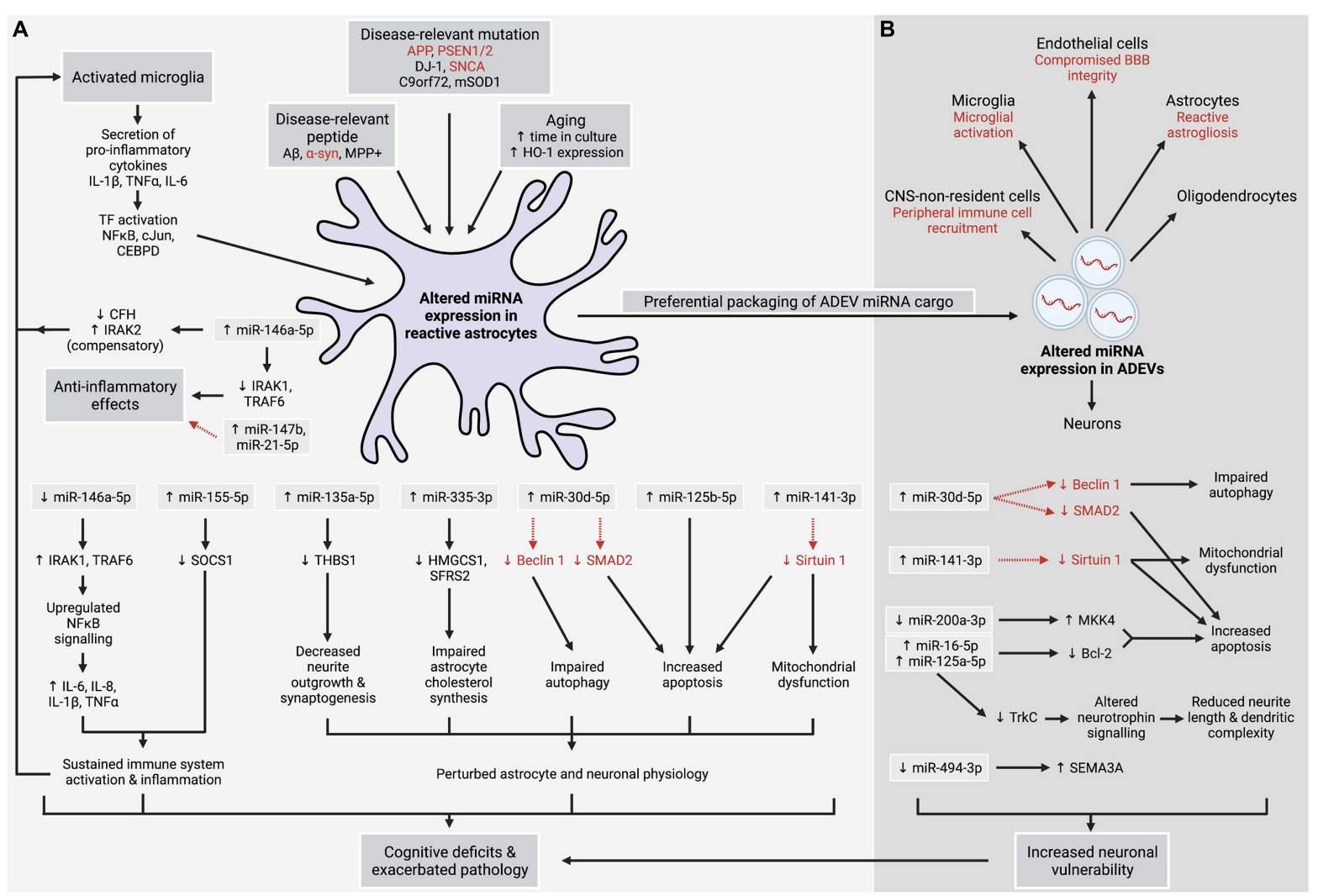

FIGURE 1 | Altered expression of miRNA in astrocytes (A) and astrocyte-derived extracellular vesicles (ADEVs) (B), arising from neurodegenerative, inflammatory, and ageing processes, contributes to sustained central nervous system (CNS) inflammation, neuronal injury, dysregulated autophagy, and mitochondrial dysfunction in astrocytes and neurons, and increased apoptosis. Uptake of ADEVs by neurons and other cell types is suggested to have numerous downstream effects. Together, these insults can exacerbate CNS pathology and contribute to the cognitive and motor symptoms observed in neurodegenerative conditions, indicating that dysregulated expression of astrocytic miRNA plays a central role in neurodegenerative disease. Alternatively, anti-inflammatory effects are observed in response to certain stimuli. Red font and dashed red arrows denote postulated links.

after accounting for age and post mortem delay (Schipper, 2000). Thus, HO-1-induced alterations to astrocytic miRNA expression may contribute to the increased risk of developing a neurodegenerative disease in older age.

\section{Dysregulation of MicroRNA in Astrocytes in Response to Inflammation}

Considerable evidence demonstrates that miRNA expression is altered in astrocytes and/or ADEVs following exposure to the pro-inflammatory cytokines interleukin-1-beta (IL-1 $\beta$ ), tumour necrosis factor-alpha $(\mathrm{TNF} \alpha)$ and interleukin-6 (IL-6) (Junker et al., 2009; Pogue et al., 2010; Tarassishin et al., 2011; Iyer et al., 2012; Lu et al., 2015; van Scheppingen et al., 2016, 2018; Chaudhuri et al., 2018; Korotkov et al., 2018; Gayen et al., 2020; Table 1). Release of IL-1 $\beta, T N F \alpha$ and IL- 6 by activated microglia has been observed in $\mathrm{AD}$ and $\mathrm{PD}$, while reactive microglia and elevated levels of these and other cytokines have been observed in ALS (Smith et al., 2012). Furthermore, activated astrocytes also release these cytokines (Choi et al., 2014; van Scheppingen et al., 2018), contributing to the chronic inflammatory state observed in neurodegenerative diseases.
Exposure of astrocytes to IL-1 $\beta$ and TNF $\alpha$ upregulates the expression of numerous miRNA (Table 1), including miR-146a$5 \mathrm{p}$ and miR-155-5p. Interestingly, co-upregulation of miR-146a$5 p$ and miR-155-5p has been observed for both IL-1 $\beta$ - and TNF $\alpha$-treated astrocytes (Junker et al., 2009; van Scheppingen et al., 2016; Table 1), in line with observations that these miRNA can act in concert to refine cellular responses to inflammation (Mahesh and Biswas, 2019). Nuclear factor kappa-light-chainenhancer of activated B cells $(\mathrm{NF \kappa} B)$ is an inflammationassociated TF that stimulates transcription of pro-inflammatory cytokines, including IL-6, IL-8, IL-1 $\beta$, and TNF $\alpha$ (Saba et al., 2014; Shi and Sun, 2018; Figure 1A). Induction of miR-146a-5p is dependent upon NFkB signalling (Taganov et al., 2006), however, a negative feedback loop allows miR-146a-5p to temper the immune response by directly targeting interleukin-1 receptorassociated kinase 1 (IRAK1) and tumour necrosis factor receptorassociated factor 6 (TRAF6) which upregulate NFKB activity (Figure 1A). In contrast, miR-155-5p augments inflammation by reducing the expression of suppressor of cytokine signalling 1 (SOCS1), a protein that inhibits inflammatory signalling and the production of pro-inflammatory mediators (Cardoso et al., 2012; Figure 1A). 
IL-1 $\beta$ also upregulates miR-147b and miR-21-5p expression in astrocytes (van Scheppingen et al., 2018; Table 1). Increased expression of miR-147b downregulates production of IL- 6 and other pro-inflammatory cytokines in astrocytes and macrophages (Liu et al., 2009; van Scheppingen et al., 2018) suggesting that miR-147b is a negative regulator of inflammation. On the other hand, while miR-21-5p can both silence and promote NFкB signalling (Ma et al., 2011), it is generally reported to have antiinflammatory properties in the CNS (Gaudet et al., 2018), and has been shown to reduce the hypertrophic response of astrocytes to spinal cord injury (Bhalala et al., 2012; Figure 1A).

IL- $1 \beta$ or TNF $\alpha$ also alter the miRNA cargo of ADEVs and stimulate ADEV production (Dickens et al., 2017; Chaudhuri et al., 2018; Gayen et al., 2020). Significant upregulation of 27 miRNA was observed in ADEVs following treatment of astrocytes with IL-1 $\beta$, with bioinformatics analysis of miRNA targets highlighting cell death and survival as a key pathway likely affected by these changes (Gayen et al., 2020). Further investigation confirmed the IL- $1 \beta$-induced upregulation of miR30d-5p and miR-141-3p in both ADEVs and astrocytes (Gayen et al., 2020; Table 1 and Figures 1A,B). Augmented miR-30d$5 \mathrm{p}$ has been shown to upregulate apoptosis and downregulate autophagy by respectively targeting SMAD2 (Yu and Liu, 2020) and the autophagosome-associated protein Beclin 1 (Zhao et al., 2017), while increased miR-141-3p, which downregulates the neuroprotective protein Sirtuin 1, was associated with increased apoptosis and mitochondrial dysfunction (Zheng et al., 2020). Thus, similar effects could occur in both astrocytes and ADEV-ingesting cells (Figures 1A,B). In another study, ADEVs enriched in miR-16-5p, miR-125a-5p, and miR-125b$5 p$ secreted by IL- $1 \beta$ - and TNF $\alpha$-treated astrocytes reduced neurite length and dendritic complexity in primary neurons (Chaudhuri et al., 2018). Both miR-16-5p and miR-125a-5p target two key components of the neurotrophin signalling pathwayNtrk3, which encodes the neurotrophin TrkC receptor, and anti-apoptotic protein Bcl-2 (Figure 1B). Inhibiting miR-16$5 p$ and miR-125a-5p in ADEVs abolished synaptic injury and restored neuronal activity. In contrast to Gayen et al. (2020), no changes to cellular miRNA expression in IL-1 $\beta$ - or TNF $\alpha$-treated astrocytes were observed in this study (Chaudhuri et al., 2018). This, alongside discrepancies in the specific miRNA altered by IL-1 $\beta$ treatment between these studies, may reflect differences between species or in the duration and concentration of IL-1 $\beta$ used (Table 1).

Finally, IL-6 exposure was found to induce both astrogliosis and a significant increase in astrocytic miR-125b-5p (Pogue et al., 2010; Table 1), a miRNA that has been associated with apoptosis, inflammation and oxidative stress that is upregulated in the $\mathrm{AD}$ brain (Jin et al., 2018; Figure 1A).

\section{Dysregulation of MicroRNA in Astrocytes in Alzheimer's Disease}

Amyloid-beta $(\mathrm{A} \beta)$ accumulates in the $\mathrm{AD}$ brain due to impaired clearance mechanisms (Mawuenyega et al., 2010; Wildsmith et al., 2013), with monomers aggregating to form synaptotoxic oligomers and protofibrils (Klyubin et al., 2012) and ultimately forming the extracellular deposits of aggregated $A \beta$ that are a characteristic hallmark of AD. Astrocytes have been shown to surround these plaques (Olabarria et al., 2010; Perez-Nievas and Serrano-Pozo, 2018) and ingest $\mathrm{A} \beta$ molecules (Jones et al., 2013; Söllvander et al., 2016). Exposure to aggregated $A \beta$ induces reactive astrogliosis and increases astrocytic production of inflammatory mediators (Singh et al., 2020), while ingestion of aggregated $A \beta$ can impair lysosome function, hinder astrocytic degradation of $A \beta$ protofibrils and alter the cargo of ADEVs (Söllvander et al., 2016).

Accumulating evidence shows that in vitro exposure of astrocytes to $\mathrm{A} \beta$ alters miRNA expression. For example, miR155 was significantly elevated in astrocytes treated with $A \beta$ fibrils (Guedes et al., 2014; presumably miR-155-5p). A $\beta$ can activate c-Jun N-terminal kinase (JNK), which subsequently activates the TF c-Jun (Yarza et al., 2016). Indeed, the A $\beta$-mediated increase in miR-155-5p in astrocytes was reduced when c-Jun was silenced (Guedes et al., 2014). Furthermore, expression of both c-Jun and miR-155-5p was upregulated in the brains of 3xTg transgenic AD mice. Notably, A $\beta$ pathology was associated with decreased expression of the miR-155-5p target Socs1 (Figure 1A), likely contributing to an increase in inflammatory processes in the AD brain alongside increased expression of IL-6 (Guedes et al., 2014) and other pro-inflammatory molecules.

Additionally, significant elevation of miR-146a-5p was observed following exposure of human astrocytes to $A \beta$, either alone or in conjunction with IL-1 $\beta$ (Cui et al., 2010; Table 1) or $\mathrm{TNF} \alpha$ (Li et al., 2011). This occurred alongside increased activation of NFKB (Cui et al., 2010). Increased miR-146a-5p was associated with decreased expression of miR-146a-5p targets complement factor $\mathrm{H}(\mathrm{CFH})$, TSPAN12 and IRAK1 (Li et al., 2011), while increased IRAK1 levels were observed following inhibition of miR-146a-5p (Cui et al., 2010). Interestingly, a compensatory increase in IRAK2, which also upregulates NFкB signalling (Saba et al., 2014; Shi and Sun, 2018), was observed in both $\mathrm{AD}$ brain and $\mathrm{A} \beta$-treated astrocytes (Cui et al., 2010) and is likely to counter any protective effects of IRAK1 downregulation. Furthermore, as CFH acts as an inhibitor of the complement cascade, the miR-146a$5 \mathrm{p}$-mediated downregulation of $\mathrm{CFH}$ combined with IRAK2 upregulation following astrocytic exposure to $A \beta$ is likely to result in sustained activation of the immune response, with the enhanced astrocytic production and secretion of NFкBregulated pro-inflammatory cytokines contributing to continued activation of both microglia and astrocytes (Li et al., 2011; Figure 1A).

Increased expression of the cytokine-responsive TF CCAATenhancer binding protein-delta (CEBPD) has been observed in the brains of AD patients (Li et al., 2004), the APP/PS1 AD mouse model (Ko et al., 2012) and, notably, in astrocytes treated with pro-inflammatory cytokines (Chu et al., 2016) or surrounding A $\beta$ plaques (Li et al., 2004). CEBPD induces transcription of miR-135a-5p, a miRNA that negatively regulates thrombospondin 1 (THBS1), a neurotrophic factor secreted by astrocytes to enhance neurite outgrowth and synaptogenesis (Sofroniew and Vinters, 2010; Chu et al., 2016; Figure 1A). Increased miR-135a-5p expression has been reported in the 
brains of APP/PS1 mice (Chu et al., 2016). Reducing CEBPD levels or inhibiting miR-135a-5p in APP/PS1 mice improved performance on learning and memory tasks.

\section{Dysregulation of MicroRNA in Astrocytes in Parkinson's Disease}

Though PD is characterised by the progressive loss of dopaminergic neurons in the substantia nigra resulting in movement dysfunction, astrocytes are also affected by PD pathophysiology (Booth et al., 2017), including the ingestion of neurotoxic aggregates of alpha-synuclein ( $\alpha$-syn) protein (Wakabayashi et al., 2000; Rostami et al., 2017), a key component of the neuronal Lewy bodies present in PD.

Mutations in the $\alpha$-syn-encoding gene SNCA are associated with increased risk of developing PD (Campêlo and Silva, 2017), while DJ-1 mutations give rise to a rare inherited form of $\mathrm{PD}$, likely due to loss of numerous protective functions of the DJ-1 protein (Kahle et al., 2009; Giaime et al., 2010; Ariga et al., 2013). Investigation into the effects of $\alpha$-syn dysfunction, aggregation and SNCA mutations on astrocytic miRNA expression is surprisingly lacking. However, interferon gamma (IFN- $\gamma$ )-treated astrocytes from DJ-1 knock out mice demonstrate a robust increase in miR-155$5 \mathrm{p}$ and concomitant downregulation of Socs1 (Figure 1A), suggesting that $D J-1$ mutations in familial $\mathrm{PD}$ may alter astrocytic regulation of miR-155-5p levels in response to inflammation (Kim et al., 2014; Table 1). As mentioned, elevated miR-155-5p and reduced Socs1 expression was observed following exposure of astrocytes to $A \beta$ (Guedes et al., 2014), suggesting that miRNA-mediated disruption of normal astrocyte responses to CNS inflammation may be a key feature of both diseases.

The neurotoxin 1-methyl-4-phenyl-1,2,3,6tetrahydropyridine (MPTP) and metabolite $\mathrm{MPP}+$ are taken up into neurons via dopamine transporters, resulting in selective degeneration of dopaminergic neurons accompanied by parkinsonian symptoms (Kitayama et al., 1998) and increased expression of $\alpha$-syn protein in differentiated PC12 cells (Zheng et al., 2020). Interestingly, exposure of astrocytes to $\mathrm{MPP}+$ induces astrogliosis and the production of proinflammatory cytokines (Yu et al., 2016) and alters the miRNA cargo of ADEVs (Shakespear et al., 2020; Table 1). One notable change in ADEVs is the downregulation of miR-200a-3p, which targets the apoptosis-associated kinase Map2k4. Reduced transfer of miR-200a-3p to neurons via ADEVs rendered neurons more vulnerable to neurotoxic stimuli (Shakespear et al., 2020; Figure 1B). Similarly, exposing dopaminergic neurons to ADEVs enriched in miR-34a-5p increased neuronal susceptibility to neurotoxins due to the negative regulation of Bcl-2 by miR-34a (Mao et al., 2015; presumably miR-34a-5p). As miR-34a-5p expression was induced by exposing astrocytes to the inflammatory stimulus lipopolysaccharide, the presence of other ADEV components that may have contributed to neuronal loss cannot be ruled out. However, co-administration of miR-34a-5p inhibitors alongside miR-34a-5p-enriched ADEVs reduced neuronal vulnerability to neurotoxins (Mao et al., 2015). Interestingly, elevated expression of miR-34a-5p has also been observed in the brains of sporadic AD patients (Zhao et al., 2019) and in APP/PS1 mice (Wang et al., 2009).

\section{Dysregulation of MicroRNA in Astrocytes in Amyotrophic Lateral Sclerosis}

ALS is characterised by progressive paralysis and muscle atrophy arising from the degeneration of motor neurons in the brain and spinal cord (Joilin et al., 2019). While the mechanisms underlying this degeneration are not completely elucidated, both astrocytes and ADEVs are known to play a significant role (Pehar et al., 2017; Chen et al., 2019). Although more than 20 genes are associated with ALS, mutations in the SOD1 and C9orf72 genes are among the most common and play a causative role in the development of both familial and sporadic forms of ALS (Tripolszki et al., 2017). Alongside this, cytosolic accumulation and aggregation of TAR DNA-binding protein 43 (TDP-43) is present in the majority of patients with familial or sporadic ALS. While TDP-43 is known to sequester miRNA in neurons (Zuo et al., 2021), there is no current literature exploring its role in the regulation of miRNA in astrocytes.

Altered expression of several miRNA has been observed, however, in both primary astrocytes and ADEV from the SOD1G93A (mSOD1) mouse model of ALS (Gomes et al., 2019, 2020), though, curiously, others found no differences in ADEV cargo between mSOD1 and wildtype mice (Jovičić and Gitler, 2017). Interestingly, Gomes et al. $(2019,2020)$ reported that the direction of change was dependent on the CNS region from which the astrocytes were derived. Cortical mSOD1 astrocytes had reduced levels of miR-21-5p and miR-146a-5p (Gomes et al., 2019) (Table 1), whereas increased expression of both these miRNA and miR-155-5p were identified in spinal cord mSOD1 astrocytes (Gomes et al., 2020). Markedly, all three miRNA were downregulated in mSOD1 ADEVs regardless of the region of origin (Gomes et al., 2020). Reduced expression of anti-inflammatory miRNAs miR-146a-5p and miR-21-5p in cortical mSOD1 astrocytes was proposed to contribute to the neuronal damage and mitochondrial dysfunction observed following co-culture of reactive astrocytes and motor neurons (Gomes et al., 2019).

Another study identified alterations to the miRNA cargo of ADEVs secreted by directly reprogrammed human astrocytes (iAstrocytes) derived from ALS patient fibroblasts with the C9orf72 mutation compared to ADEVs from control iAstrocytes (Varcianna et al., 2019). One significantly downregulated miRNA was miR-494-3p, which targets SEMA3A mRNA (Figure 1B). Though SEMA3A acts as a guidance signal for developing axons (Carulli et al., 2021), aberrant SEMA3A expression has been observed in ALS (Körner et al., 2016) and is suggested to contribute to neuronal apoptosis (Carulli et al., 2021). Notably, uptake of ALS patient-derived ADEVs by motor neurons induced neuronal death (Varcianna et al., 2019), likely due to a reduction in miR-494-3p levels in neurons following ADEV internalisation. Accordingly, restoring neuronal levels of miR-494-3p with a mimic reduced SEMA3A expression and increased neurite length and motor neuron viability (Varcianna et al., 2019).

Interestingly, there were no miRNA alterations in common between astrocytes from the mSOD1 and C9orf72 models, 
suggesting that the genetic basis of ALS leads to differential effects on ADEV miRNA cargo. Mutation-associated differences in ADEV secretion have also been observed. Fewer ADEVs were released by C9orf72 iAstrocytes (Varcianna et al., 2019), whereas primary murine mSOD1 astrocytes had enhanced ADEV secretion (Basso et al., 2013).

\section{DISCUSSION}

As summarised in Figure 1, significant alterations to astrocytic miRNA expression arise from the pathological processes underlying or contributing to neurodegenerative disease, including genetic mutations, accumulation of aggregated peptides, pro-inflammatory cytokine release by activated microglia, and ageing. Altered activity of key TFs in astrocytes appears to result in aberrant transcription of miRNA which ultimately affects the health and function of surrounding cells, particularly neurons. Furthermore, the curated nature of alterations to ADEV-associated miRNA indicates that ADEV-mediated intercellular communication is an important component of the astrocyte response to neurodegeneration with the potential for widespread, cell non-autonomous effects and propagation of pathology throughout the brain because of ADEV uptake. Many of the genes targeted by dysregulation of astrocytic and ADEV-associated miRNA converge upon common pathways including apoptosis, inflammation, TF signalling, and the loss of normal or neuroprotective astrocytic functions or proteins. This may underpin chronic CNS inflammation and increase neuronal susceptibility to neurodegenerative processes which may hasten disease onset and exacerbate symptoms. Furthermore, significant crosstalk between astrocytes and other cell types, as well as perturbed regulation of miRNA transcription, may amplify the effects of disrupted astrocytic miRNA expression.

Our understanding of perturbed astrocytic miRNA expression in neurodegenerative disease remains limited, especially in regard to ageing. Discrepancies regarding which miRNA are significantly altered in astrocytes in neurodegenerative disorders will hopefully be resolved with further investigation. Furthermore, while various alterations to the protein cargo of plasma ADEVs from AD patients have been reported (Goetzl et al., 2016, 2018; Winston et al., 2019), no studies have investigated miRNA changes in ADEVs in AD. There is also a profound lack of investigation into altered miRNA expression

\section{REFERENCES}

Ariga, H., Takahashi-Niki, K., Kato, I., Maita, H., Niki, T., and Iguchi-Ariga S. M. M. (2013). Neuroprotective function of DJ-1 in Parkinson's disease. Oxid. Med. Cell. Longev. 2013:683920. doi: 10.1155/2013/683920

Bai, Y., Su, X., Piao, L., Jin, Z., and Jin, R. (2021). Involvement of astrocytes and microRNA dysregulation in neurodegenerative diseases: from pathogenesis to therapeutic potential. Front. Mol. Neurosci. 14:556215. doi: 10.3389/fnmol.2021. 556215

Baldwin, K. T., and Eroglu, C. (2017). Molecular mechanisms of astrocyte-induced synaptogenesis. Curr. Opin. Neurobiol. 45, 113-120. doi: 10.1016/j.conb.2017. 05.006 in astrocytes and ADEVs in relation to Huntington's disease and non-Alzheimer's type dementias, such as frontotemporal dementia and vascular dementia.

Research has largely focussed on small groups of differentially expressed miRNA and their mRNA targets, often selected based on known relationships to specific cellular processes or relevant target genes. Comprehensive miRNA expression profiling with methods such as RNA-sequencing in conjunction with bioinformatics tools would ensure that important changes in miRNA expression do not go undetected, while the use of upto-date miRNA nomenclature will reduce ambiguity regarding which miRNA strand mediates the effects described. Researchers investigating disease-driven miRNA alterations in astrocytes should ensure the experimental model used is as relevant to the disease process as possible, ideally utilising human rather than rodent models and focussing on alterations caused by genetic mutations or causative agents pertinent to the disease of interest. Observations of ageing-induced alterations to miRNA expression highlight the critical importance of having agematched healthy controls. Finally, while in vitro experiments assist in uncovering the mechanistic links between altered miRNA expression and downstream outcomes, the short time courses of such experiments should be married with longer term, in vivo observations from post mortem human brain or aged animal models to ensure the effects of dysregulated astrocytic miRNA expression are placed within the wider context of chronic neurodegenerative diseases.

\section{AUTHOR CONTRIBUTIONS}

AC and JW made substantial, direct, and intellectual contributions to the work, and approved it for publication.

\section{FUNDING}

This work was supported by a Brain Research New Zealand, Rangahau Roro Aotearoa Doctoral Scholarship to AC.

\section{ACKNOWLEDGMENTS}

We acknowledge the support of the Department of Anatomy, University of Otago. Figure 1 was created with Biorender.com.

Basso, M., Pozzi, S., Tortarolo, M., Fiordaliso, F., Bisighini, C., Pasetto, L., et al. (2013). Mutant copper-zinc superoxide dismutase (SOD1) induces protein secretion pathway alterations and exosome release in astrocytes: implications for disease spreading and motor neuron pathology in amyotrophic lateral sclerosis. J. Biol. Chem. 288, 15699-15711. doi: 10.1074/jbc.M112.42 5066

Berson, A., Nativio, R., Berger, S. L., and Bonini, N. M. (2018). Epigenetic regulation in neurodegenerative diseases. Trends Neurosci. 41, 587-598. doi: 10.1016/j.tins.2018.05.005

Bhalala, O. G., Pan, L., Sahni, V., McGuire, T. L., Gruner, K., Tourtellotte, W. G., et al. (2012). microRNA-21 regulates astrocytic response following spinal cord injury. J. Neurosci. 32, 17935-17947. doi: 10.1523/JNEUROSCI.3860- 12.2012 
Boisvert, M. M., Erikson, G. A., Shokhirev, M. N., and Allen, N. J. (2018). The aging astrocyte transcriptome from multiple regions of the mouse brain. Cell Rep. 22, 269-285. doi: 10.1016/j.celrep.2017.12.039

Booth, H. D. E., Hirst, W. D., and Wade-Martins, R. (2017). The role of astrocyte dysfunction in Parkinson's disease pathogenesis. Trends Neurosci. 40, 358-370. doi: 10.1016/j.tins.2017.04.001

Cai, S., Shi, G. S., Cheng, H. Y., Zeng, Y. N., Li, G., Zhang, M., et al. (2017). Exosomal miR-7 mediates bystander autophagy in lung after focal brain irradiation in mice. Int. J. Biol. Sci. 13, 1287-1296. doi: 10.7150/ijbs.18890

Campêlo, C. L. D. C., and Silva, R. H. (2017). Genetic variants in SNCA and the risk of sporadic Parkinson's disease and clinical outcomes: a review. Parkinsons Dis. 2017:4318416. doi: 10.1155/2017/4318416

Cardoso, A. L., Guedes, J. R., Pereira de Almeida, L., and Pedroso de Lima, M. C. (2012). miR-155 modulates microglia-mediated immune response by down-regulating SOCS-1 and promoting cytokine and nitric oxide production. Immunology 135, 73-88. doi: 10.1111/j.1365-2567.2011.03514.x

Carulli, D., de Winter, F., and Verhaagen, J. (2021). Semaphorins in adult nervous system plasticity and disease. Front. Synaptic Neurosci. 13:672891. doi: 10.3389/ fnsyn.2021.672891

Chaudhuri, A. D., Dastgheyb, R. M., Yoo, S. W., Trout, A., Talbot, C. C., Hao, H., et al. (2018). TNF $\alpha$ and IL- $1 \beta$ modify the miRNA cargo of astrocyte shed extracellular vesicles to regulate neurotrophic signaling in neurons. Cell Death Dis. 9:363. doi: 10.1038/s41419-018-0369-4

Chen, T. S., Lai, R. C., Lee, M. M., Choo, A. B. H., Lee, C. N., and Lim, S. K. (2010). Mesenchymal stem cell secretes microparticles enriched in pre-microRNAs. Nucleic Acids Res. 38, 215-224. doi: 10.1093/nar/gkp857

Chen, Y., Xia, K., Chen, L., and Fan, D. (2019). Increased interleukin-6 levels in the astrocyte-derived exosomes of sporadic amyotrophic lateral sclerosis patients. Front. Neurosci. 13:574. doi: 10.3389/fnins.2019.00574

Chipman, L. B., and Pasquinelli, A. E. (2019). miRNA targeting: growing beyond the seed. Trends Genet. 35, 215-222. doi: 10.1016/j.tig.2018.12.005

Choi, S. S., Lee, H. J., Lim, I., Satoh, J. I., and Kim, S. U. (2014). Human astrocytes: secretome profiles of cytokines and chemokines. PLoS One 9:e92325. doi: 10. 1371/journal.pone.0092325

Chu, Y. Y., Ko, C. Y., Wang, W. J., Wang, S. M., Gean, P. W., Kuo, Y. M., et al. (2016). Astrocytic CCAAT/enhancer binding protein $\delta$ regulates neuronal viability and spatial learning ability via miR-135a. Mol. Neurobiol. 53, 41734188. doi: 10.1007/s12035-015-9359-z

Cooper-Knock, J., Kirby, J., Ferraiuolo, L., Heath, P. R., Rattray, M., and Shaw, P. J. (2012). Gene expression profiling in human neurodegenerative disease. Nat. Rev. Neurol. 8, 518-530. doi: 10.1038/nrneurol.2012.156

Cui, J. G., Li, Y. Y., Zhao, Y., Bhattacharjee, S., and Lukiw, W. J. (2010). Differential regulation of interleukin-1 receptor-associated kinase-1 (IRAK-1) and IRAK2 by microRNA-146a and NF- $\kappa \mathrm{B}$ in stressed human astroglial cells and in Alzheimer disease. J. Biol. Chem. 285, 38951-38960. doi: 10.1074/jbc.M110. 178848

Danka Mohammed, C. P., Park, J. S., Nam, H. G., and Kim, K. (2017). MicroRNAs in brain aging. Mech. Ageing Dev. 168, 3-9. doi: 10.1016/j.mad.2017.01.007

Dickens, A. M., Tovar-Y-Romo, L. B., Yoo, S. W., Trout, A. L., Bae, M., Kanmogne, M., et al. (2017). Astrocyte-shed extracellular vesicles regulate the peripheral leukocyte response to inflammatory brain lesions. Sci. Signal. 10:eaai7696. doi: 10.1126/scisignal.aai7696

Escartin, C., Galea, E., Lakatos, A., O’Callaghan, J. P., Petzold, G. C., SerranoPozo, A., et al. (2021). Reactive astrocyte nomenclature, definitions, and future directions. Nat. Neurosci. 24, 312-325. doi: 10.1038/s41593-020-00783-4

Ferro, E., Enrico Bena, C., Grigolon, S., and Bosia, C. (2019). From endogenous to synthetic microRNA-mediated regulatory circuits: an overview. Cells 8:1540. doi: $10.3390 /$ cells 8121540

Gagliardi, D., Comi, G. P., Bresolin, N., and Corti, S. (2019). MicroRNAs as regulators of cell death mechanisms in amyotrophic lateral sclerosis. J. Cell. Mol. Med. 23, 1647-1656. doi: 10.1111/jcmm.13976

Gaudet, A. D., Fonken, L. K., Watkins, L. R., Nelson, R. J., and Popovich, P. G. (2018). MicroRNAs: roles in regulating neuroinflammation. Neuroscientist 24, 221-245. doi: 10.1177/1073858417721150

Gayen, M., Bhomia, M., Balakathiresan, N., and Knollmann-Ritschel, B. (2020). Exosomal microRNAs released by activated astrocytes as potential neuroinflammatory biomarkers. Int. J. Mol. Sci. 21:2312. doi: 10.3390/ ijms 21072312
Giaime, E., Sunyach, C., Druon, C., Scarzello, S., Robert, G., Grosso, S., et al. (2010). Loss of function of DJ-1 triggered by Parkinson's disease-associated mutation is due to proteolytic resistance to caspase-6. Cell Death Differ. 17, 158-169. doi: $10.1038 /$ cdd.2009.116

Goetzl, E. J., Mustapic, M., Kapogiannis, D., Eitan, E., Lobach, I. V., Goetzl, L., et al. (2016). Cargo proteins of plasma astrocyte-derived exosomes in Alzheimer's disease. FASEB J. 30, 3853-3859. doi: 10.1096/fj.201600756R

Goetzl, E. J., Schwartz, J. B., Abner, E. L., Jicha, G. A., and Kapogiannis, D. (2018). High complement levels in astrocyte-derived exosomes of Alzheimer disease. Ann. Neurol. 83, 544-552. doi: 10.1002/ana.25172

Goh, S. Y., Chao, Y. X., Dheen, S. T., Tan, E. K., and Tay, S. S. W. (2019). Role of microRNAs in Parkinson's disease. Int. J. Mol. Sci. 20:5649. doi: 10.3390/ ijms20225649

Gomes, C., Cunha, C., Nascimento, F., Ribeiro, J. A., Vaz, A. R., and Brites, D. (2019). Cortical neurotoxic astrocytes with early ALS pathology and miR-146a deficit replicate gliosis markers of symptomatic SOD1G93A mouse model. Mol. Neurobiol. 56, 2137-2158. doi: 10.1007/s12035-018-1220-8

Gomes, C., Sequeira, C., Barbosa, M., Cunha, C., Vaz, A. R., and Brites, D. (2020). Astrocyte regional diversity in ALS includes distinct aberrant phenotypes with common and causal pathological processes. Exp. Cell Res. 395:112209. doi: 10.1016/j.yexcr.2020.112209

Groot, M., and Lee, H. (2020). Sorting mechanisms for microRNAs into extracellular vesicles and their associated diseases. Cells 9:1044. doi: 10.3390/ cells 9041044

Guedes, J. R., Custódia, C. M., Silva, R. J., de Almeida, L. P., de Lima, M. C. P., and Cardoso, A. L. (2014). Early miR-155 upregulation contributes to neuroinflammation in Alzheimer's disease triple transgenic mouse model. Hum. Mol. Genet. 23, 6286-6301. doi: 10.1093/hmg/ddu348

Habib, N., McCabe, C., Medina, S., Varshavsky, M., Kitsberg, D., Dvir-Szternfeld, R., et al. (2020). Disease-associated astrocytes in Alzheimer's disease and aging. Nat. Neurosci. 23, 701-706. doi: 10.1038/s41593-020-0624-8

Hirose, W., Ikematsu, K., and Tsuda, R. (2003). Age-associated increases in heme oxygenase-1 and ferritin immunoreactivity in the autopsied brain. Leg. Med. 5, S360-S366. doi: 10.1016/S1344-6223(02)00133-5

Hou, Y., Dan, X., Babbar, M., Wei, Y., Hasselbalch, S. G., Croteau, D. L., et al. (2019). Ageing as a risk factor for neurodegenerative disease. Nat. Rev. Neurol. 15, 565-581. doi: 10.1038/s41582-019-0244-7

Ibáñez, F., Montesinos, J., Ureña-Peralta, J. R., Guerri, C., and Pascual, M. (2019). TLR4 participates in the transmission of ethanol-induced neuroinflammation via astrocyte-derived extracellular vesicles. J. Neuroinflammation 16:136. doi: 10.1186/s12974-019-1529-x

Inukai, S., Pincus, Z., de Lencastre, A., and Slack, F. J. (2018). A microRNA feedback loop regulates global microRNA abundance during aging. RNA 24, 159-172. doi: 10.1261/rna.062190.117

Ipas, H., Guttin, A., and Issartel, J.-P. (2015). Exosomal microRNAs in tumoral U87 MG versus normal astrocyte cells. MicroRNA 4, 131-145. doi: 10.2174/ 2211536604666150820115707

Iwakawa, H.-O., and Tomari, Y. (2015). The functions of microRNAs: mRNA decay and translational repression. Trends Cell Biol. 25, 651-665. doi: 10.1016/ j.tcb.2015.07.011

Iyer, A., Zurolo, E., Prabowo, A., Fluiter, K., Spliet, W. G. M., van Rijen, P. C., et al. (2012). MicroRNA-146a: a key regulator of astrocyte-mediated inflammatory response. PLoS One 7:e44789. doi: 10.1371/journal.pone.0044789

Jin, Y., Tu, Q., and Liu, M. (2018). MicroRNA-125b regulates Alzheimer's disease through SphK1 regulation. Mol. Med. Rep. 18, 2373-2380. doi: 10.3892/mmr. 2018.9156

Joilin, G., Leigh, P. N., Newbury, S. F., and Hafezparast, M. (2019). An overview of microRNAs as biomarkers of ALS. Front. Neurol. 10:186. doi: 10.3389/fneur. 2019.00186

Jones, R. S., Minogue, A. M., Connor, T. J., and Lynch, M. A. (2013). Amyloid- $\beta$-induced astrocytic phagocytosis is mediated by CD36, CD47 and RAGE. J. Neuroimmune Pharmacol. 8, 301-311. doi: 10.1007/s11481-0129427-3

Jovičić, A., and Gitler, A. D. (2017). Distinct repertoires of microRNAs present in mouse astrocytes compared to astrocyte-secreted exosomes. PLoS One 12:e0171418. doi: 10.1371/journal.pone.0171418

Junker, A., Krumbholz, M., Eisele, S., Mohan, H., Augstein, F., Bittner, R., et al. (2009). MicroRNA profiling of multiple sclerosis lesions identifies modulators 
of the regulatory protein CD47. Brain 132, 3342-3352. doi: 10.1093/brain/ awp300

Kahle, P. J., Waak, J., and Gasser, T. (2009). DJ-1 and prevention of oxidative stress in Parkinson's disease and other age-related disorders. Free Radic. Biol. Med. 47, 1354-1361. doi: 10.1016/j.freeradbiomed.2009.08.003

Kim, J.-H., Jou, I., and Joe, E.-H. (2014). Suppression of miR-155 expression in IFN- $\gamma$-treated astrocytes and microglia by DJ-1: a possible mechanism for maintaining SOCS1 expression. Exp. Neurobiol. 23, 148-154. doi: 10.5607/en. 2014.23.2.148

Kitayama, S., Mitsuhata, C., Davis, S., Wang, J. B., Sato, T., Morita, K., et al. (1998). $\mathrm{MPP}+$ toxicity and plasma membrane dopamine transporter: study using cell lines expressing the wild-type and mutant rat dopamine transporters. Biochim. Biophys. Acta 1404, 305-313. doi: 10.1016/S0167-4889(98)00071-8

Klyubin, I., Cullen, W. K., Hu, N. W., and Rowan, M. J. (2012). Alzheimer's disease $\mathrm{A} \beta$ assemblies mediating rapid disruption of synaptic plasticity and memory. Mol. Brain 5:25. doi: 10.1186/1756-6606-5-25

Ko, C. Y., Chang, L. H., Lee, Y. C., Sterneck, E., Cheng, C. P., Chen, S. H., et al. (2012). CCAAT/enhancer binding protein delta (CEBPD) elevating PTX3 expression inhibits macrophage-mediated phagocytosis of dying neuron cells. Neurobiol. Aging 33, 422.e11-422.e25. doi: 10.1016/j.neurobiolaging.2010. 09.017

Körner, S., Böselt, S., Wichmann, K., Thau-Habermann, N., Zapf, A., Knippenberg, S., et al. (2016). The axon guidance protein semaphorin $3 \mathrm{~A}$ is increased in the motor cortex of patients with amyotrophic lateral sclerosis. J. Neuropathol. Exp. Neurol. 75, 326-333. doi: 10.1093/jnen/nlw003

Korotkov, A., Broekaart, D. W. M., van Scheppingen, J., Anink, J. J., Baayen, J. C., Idema, S., et al. (2018). Increased expression of matrix metalloproteinase 3 can be attenuated by inhibition of microRNA-155 in cultured human astrocytes. J. Neuroinflammation 15:211. doi: 10.1186/s12974-018-1245-y

Kriaučiūnaitė, K., Kaušylè, A., Pajarskienè, J., Tunaitis, V., Lim, D., Verkhratsky, A., et al. (2021). Immortalised hippocampal astrocytes from 3xTG-AD mice fail to support BBB integrity in vitro: role of extracellular vesicles in glialendothelial communication. Cell. Mol. Neurobiol. 41, 551-562. doi: 10.1007/ s10571-020-00871-w

Kwon, M. J., Kim, S., Han, M. H., and Lee, S. B. (2016). Epigenetic changes in neurodegenerative diseases. Mol. Cells 39, 783-789. doi: 10.14348/molcells. 2016.0233

Lee, H. K., Bier, A., Cazacu, S., Finniss, S., Xiang, C., Twito, H., et al. (2013). MicroRNA-145 is downregulated in glial tumors and regulates glioma cell migration by targeting connective tissue growth factor. PLoS One 8:e54652. doi: 10.1371 /journal.pone.0054652

Li, R., Strohmeyer, R., Liang, Z., Lue, L. F., and Rogers, J. (2004). CCAAT/enhancer binding protein $\delta(\mathrm{C} / \mathrm{EBP} \delta)$ expression and elevation in Alzheimer's disease. Neurobiol. Aging 25, 991-999. doi: 10.1016/j.neurobiolaging.2003. 10.016

Li, Y. Y., Cui, J. G., Dua, P., Pogue, A. I., Bhattacharjee, S., and Lukiw, W. J. (2011). Differential expression of miRNA-146a-regulated inflammatory genes in human primary neural, astroglial and microglial cells. Neurosci. Lett. 499, 109-113. doi: 10.1016/j.neulet.2011.05.044

Liao, K., Niu, F., Hu, G., Yang, L., Dallon, B., Villarreal, D., et al. (2020). Morphine-mediated release of miR-138 in astrocyte-derived extracellular vesicles promotes microglial activation. J. Extracell. Vesicles 10:e12027. doi: 10.1002/jev2.12027

Lin, S. H., Song, W., Cressatti, M., Zukor, H., Wang, E., and Schipper, H. M. (2015). Heme oxygenase-1 modulates microRNA expression in cultured astroglia: implications for chronic brain disorders. Glia 63, 1270-1284. doi: 10.1002/glia. 22823

Linnerbauer, M., Wheeler, M. A., and Quintana, F. J. (2020). Astrocyte crosstalk in CNS inflammation. Neuron 108, 608-622. doi: 10.1016/j.neuron.2020.08.012

Liu, G., Friggeri, A., Yang, Y., Park, Y. J., Tsuruta, Y., and Abraham, E. (2009). miR147, a microRNA that is induced upon Toll-like receptor stimulation, regulates murine macrophage inflammatory responses. Proc. Natl. Acad. Sci. U.S.A. 106, 15819-15824. doi: 10.1073/pnas.0901216106

Lu, Y., Cao, D. L., Jiang, B. C., Yang, T., and Gao, Y. J. (2015). MicroRNA-146a$5 \mathrm{p}$ attenuates neuropathic pain via suppressing TRAF6 signaling in the spinal cord. Brain Behav. Immun. 49, 119-129. doi: 10.1016/j.bbi.2015.04.018

Ma, X., Becker Buscaglia, L. E., Barker, J. R., and Li, Y. (2011). MicroRNAs in NF-кB signaling. J. Mol. Cell Biol. 3, 159-166. doi: 10.1093/jmcb/mjr007
Mahesh, G., and Biswas, R. (2019). MicroRNA-155: a master regulator of inflammation. J. Interferon Cytokine Res. 39, 321-330. doi: 10.1089/jir.2018. 0155

Mao, S., Sun, Q., Xiao, H., Zhang, C., and Li, L. (2015). Secreted miR-34a in astrocytic shedding vesicles enhanced the vulnerability of dopaminergic neurons to neurotoxins by targeting Bcl-2. Protein Cell 6, 529-540. doi: 10.1007/ s13238-015-0168-y

Matejuk, A., and Ransohoff, R. M. (2020). Crosstalk between astrocytes and microglia: an overview. Front. Immunol. 11:1416. doi: 10.3389/fimmu.2020. 01416

Mawuenyega, K. G., Sigurdson, W., Ovod, V., Munsell, L., Kasten, T., Morris, J. C., et al. (2010). Decreased clearance of CNS $\beta$-amyloid in Alzheimer's disease. Science 330:1774. doi: 10.1126/science.1197623

Morales, S., Monzo, M., and Navarro, A. (2017). Epigenetic regulation mechanisms of microRNA expression. Biomol. Concepts 8, 203-212. doi: 10.1515/bmc-20170024

Neal, M., and Richardson, J. R. (2018). Epigenetic regulation of astrocyte function in neuroinflammation and neurodegeneration. Biochim. Biophys. Acta 1864, 432-443. doi: 10.1016/j.bbadis.2017.11.004

Neckles, V. N., Morton, M. C., Holmberg, J. C., Sokolov, A. M., Nottoli, T., Liu, D., et al. (2019). A transgenic inducible GFP extracellular-vesicle reporter (TIGER) mouse illuminates neonatal cortical astrocytes as a source of immunomodulatory extracellular vesicles. Sci. Rep. 9:3094. doi: 10.1038/ s41598-019-39679-0

Olabarria, M., Noristani, H. N., Verkhratsky, A., and Rodríguez, J. J. (2010). Concomitant astroglial atrophy and astrogliosis in a triple transgenic animal model of Alzheimer's disease. Glia 58, 831-838. doi: 10.1002/glia.20967

Palmer, A. L., and Ousman, S. S. (2018). Astrocytes and aging. Front. Aging Neurosci. 10:337. doi: 10.3389/fnagi.2018.00337

Pehar, M., Harlan, B. A., Killoy, K. M., and Vargas, M. R. (2017). Role and therapeutic potential of astrocytes in amyotrophic lateral sclerosis. Curr. Pharm. Des. 23, 5010-5021. doi: 10.2174/1381612823666170622095802

Pekny, M., Pekna, M., Messing, A., Steinhäuser, C., Lee, J. M., Parpura, V., et al. (2016). Astrocytes: a central element in neurological diseases. Acta Neuropathol. 131, 323-345. doi: 10.1007/s00401-015-1513-1

Perez-Nievas, B. G., and Serrano-Pozo, A. (2018). Deciphering the astrocyte reaction in Alzheimer's disease. Front. Aging Neurosci. 10:114. doi: 10.3389/ fnagi.2018.00114

Pfrieger, F. W. (2003). Role of cholesterol in synapse formation and function. Biochim. Biophys. Acta Biomembr. 1610, 271-280. doi: 10.1016/S0005-2736(03) 00024-5

Pogue, A. I., Cui, J. G., Li, Y. Y., Zhao, Y., Culicchia, F., and Lukiw, W. J. (2010). Micro RNA-125b (miRNA-125b) function in astrogliosis and glial cell proliferation. Neurosci. Lett. 476, 18-22. doi: 10.1016/j.neulet.2010.03.054

Raihan, O., Brishti, A., Molla, M. R., Li, W., Zhang, Q., Xu, P., et al. (2018). The agedependent elevation of miR-335-3p leads to reduced cholesterol and impaired memory in brain. Neuroscience 390, 160-173. doi: 10.1016/j.neuroscience.2018. 08.003

Rostami, J., Holmqvist, S., Lindström, V., Sigvardson, J., Westermark, G. T., Ingelsson, M., et al. (2017). Human astrocytes transfer aggregated alphasynuclein via tunneling nanotubes. J. Neurosci. 37, 11835-11853. doi: 10.1523/ JNEUROSCI.0983-17.2017

Saba, R., Sorensen, D. L., and Booth, S. A. (2014). MicroRNA-146a: a dominant, negative regulator of the innate immune response. Front. Immunol. 5:578. doi: 10.3389/fimmu.2014.00578

Schipper, H. M. (2000). Heme oxygenase-1: role in brain aging and neurodegeneration. Exp. Gerontol. 35, 821-830. doi: 10.1016/S0531-5565(00) 00148-0

Shaik, M. M., Tamargo, I. A., Abubakar, M. B., Kamal, M. A., Greig, N. H., and Gan, S. H. (2018). The role of microRNAs in Alzheimer's disease and their therapeutic potentials. Genes 9:174. doi: 10.3390/genes9040174

Shakespear, N., Ogura, M., Yamaki, J., and Homma, Y. (2020). Astrocyte-derived exosomal microRNA miR-200a-3p prevents MPP+-induced apoptotic cell death through down-regulation of MKK4. Neurochem. Res. 45, 1020-1033. doi: 10.1007/s11064-020-02977-5

Shi, J. H., and Sun, S. C. (2018). Tumor necrosis factor receptor-associated factor regulation of nuclear factor $\kappa \mathrm{B}$ and mitogen-activated protein kinase pathways. Front. Immunol. 9:1849. doi: 10.3389/fimmu.2018.01849 
Singh, D., Agrawal, A., Singal, C. M. S., Pandey, H. S., Seth, P., and Sharma, S. K. (2020). Sinomenine inhibits amyloid beta-induced astrocyte activation and protects neurons against indirect toxicity. Mol. Brain 13:30. doi: 10.1186/ s13041-020-00569-6

Smith, J. A., Das, A., Ray, S. K., and Banik, N. L. (2012). Role of pro-inflammatory cytokines released from microglia in neurodegenerative diseases. Brain Res. Bull. 87, 10-20. doi: 10.1016/j.brainresbull.2011.10.004

Sofroniew, M. V., and Vinters, H. V. (2010). Astrocytes: biology and pathology. Acta Neuropathol. 119, 7-35. doi: 10.1007/s00401-009-0619-8

Söllvander, S., Nikitidou, E., Brolin, R., Söderberg, L., Sehlin, D., Lannfelt, L., et al. (2016). Accumulation of amyloid- $\beta$ by astrocytes result in enlarged endosomes and microvesicle-induced apoptosis of neurons. Mol. Neurodegener. 11:38. doi: 10.1186/s13024-016-0098-z

Taganov, K. D., Boldin, M. P., Chang, K. J., and Baltimore, D. (2006). NF-кBdependent induction of microRNA miR-146, an inhibitor targeted to signaling proteins of innate immune responses. Proc. Natl. Acad. Sci. U.S.A. 103, 1248112486. doi: 10.1073/pnas.0605298103

Tarassishin, L., Loudig, O., Bauman, A., Shafit-Zagardo, B., Suh, H. S., and Lee, S. C. (2011). Interferon regulatory factor 3 inhibits astrocyte inflammatory gene expression through suppression of the proinflammatory miR-155 and miR-155*. Glia 59, 1911-1922. doi: 10.1002/glia.21233

Temido-Ferreira, M., Coelho, J. E., Pousinha, P. A., and Lopes, L. V. (2019). Novel players in the aging synapse: impact on cognition. J. Caffeine Adenosine Res. 9, 104-127. doi: 10.1089/caff.2019.0013

Tripolszki, K., Csányi, B., Nagy, D., Ratti, A., Tiloca, C., Silani, V., et al. (2017). Genetic analysis of the SOD1 and C9ORF72 genes in Hungarian patients with amyotrophic lateral sclerosis. Neurobiol. Aging 53, 195.e1-195.e5. doi: 10.1016/ j.neurobiolaging.2017.01.016

Valadi, H., Ekström, K., Bossios, A., Sjöstrand, M., Lee, J. J., and Lötvall, J. O. (2007). Exosome-mediated transfer of mRNAs and microRNAs is a novel mechanism of genetic exchange between cells. Nat. Cell Biol. 9, 654-659. doi: 10.1038/ncb1596

van Scheppingen, J., Iyer, A. M., Prabowo, A. S., Mühlebner, A., Anink, J. J., Scholl, T., et al. (2016). Expression of microRNAs miR21, miR146a, and miR155 in tuberous sclerosis complex cortical tubers and their regulation in human astrocytes and SEGA-derived cell cultures. Glia 64, 1066-1082. doi: 10.1002/ glia. 22983

van Scheppingen, J., Mills, J. D., Zimmer, T. S., Broekaart, D. W. M., Iori, V., Bongaarts, A., et al. (2018). miR147b: a novel key regulator of interleukin 1 beta-mediated inflammation in human astrocytes. Glia 66, 1082-1097. doi: 10.1002/glia.23302

Varcianna, A., Myszczynska, M. A., Castelli, L. M., O’Neill, B., Kim, Y., Talbot, J., et al. (2019). Micro-RNAs secreted through astrocyte-derived extracellular vesicles cause neuronal network degeneration in C9orf72 ALS. EBioMedicine 40, 626-635. doi: 10.1016/j.ebiom.2018.11.067

Wakabayashi, K., Hayashi, S., Yoshimoto, M., Kudo, H., and Takahashi, H. (2000). NACP/ $\alpha$-synuclein-positive filamentous inclusions in astrocytes and oligodendrocytes of Parkinson's disease brains. Acta Neuropathol. 99, 14-20. doi: 10.1007/PL00007400

Wang, X., Liu, P., Zhu, H., Xu, Y., Ma, C., Dai, X., et al. (2009). miR-34a, a microRNA up-regulated in a double transgenic mouse model of Alzheimer's disease, inhibits bcl 2 translation. Brain Res. Bull. 80, 268-273. doi: 10.1016/j. brainresbull.2009.08.006

Wildsmith, K. R., Holley, M., Savage, J. C., Skerrett, R., and Landreth, G. E. (2013). Evidence for i:, 33. doi: 10.1186/alzrt187

Willis, C. M., Nicaise, A. M., Bongarzone, E. R., Givogri, M., Reiter, C. R., Heintz, O., et al. (2020). Astrocyte support for oligodendrocyte differentiation can be conveyed via extracellular vesicles but diminishes with age. Sci. Rep. 10:828. doi: 10.1038/s41598-020-57663-x

Winston, C. N., Goetzl, E. J., Schwartz, J. B., Elahi, F. M., and Rissman, R. A. (2019). Complement protein levels in plasma astrocyte-derived exosomes are abnormal in conversion from mild cognitive impairment to Alzheimer's disease dementia. Alzheimers Dement. 11, 61-66. doi: 10.1016/j.dadm.2018.11.002

Xu, L., Cao, H., Xie, Y., Zhang, Y., Du, M., Xu, X., et al. (2019). Exosome-shuttled miR-92b-3p from ischemic preconditioned astrocytes protects neurons against oxygen and glucose deprivation. Brain Res. 1717, 66-73. doi: 10.1016/j.brainres. 2019.04.009

Yarza, R., Vela, S., Solas, M., and Ramirez, M. J. (2016). c-Jun N-terminal kinase (JNK) signaling as a therapeutic target for Alzheimer's disease. Front. Pharmacol. 6:321. doi: 10.3389/fphar.2015.00321

Yu, M., and Liu, J. (2020). MicroRNA-30d-5p promotes ovarian granulosa cell apoptosis by targeting Smad2. Exp. Ther. Med. 19, 53-60. doi: 10.3892/etm. 2019.8184

Yu, S., Wang, X., He, X., Wang, Y., Gao, S., Ren, L., et al. (2016). Curcumin exerts anti-inflammatory and antioxidative properties in 1-methyl4-phenylpyridinium ion (MPP+)-stimulated mesencephalic astrocytes by interference with TLR4 and downstream signaling pathway. Cell Stress Chaperones 21, 697-705. doi: 10.1007/s12192-016-0695-3

Zhao, F., Qu, Y., Zhu, J., Zhang, L., Huang, L., Liu, H., et al. (2017). miR-30d-5p plays an important role in autophagy and apoptosis in developing rat brains after hypoxic-ischemic injury. J. Neuropathol. Exp. Neurol. 76, 709-719. doi: 10.1093/jnen/nlx052

Zhao, S., Sheng, S., Wang, Y., Ding, L., Xu, X., Xia, X., et al. (2021). Astrocytederived extracellular vesicles: a double-edged sword in central nervous system disorders. Neurosci. Biobehav. Rev. 125, 148-159. doi: 10.1016/j.neubiorev.2021. 02.027

Zhao, Y., Jaber, V. R., LeBeauf, A., Sharfman, N. M., and Lukiw, W. J. (2019). MicroRNA-34a (miRNA-34a) mediated down-regulation of the post-synaptic cytoskeletal element SHANK3 in sporadic Alzheimer's disease (AD). Front. Neurol. 10:28. doi: 10.3389/fneur.2019.00028

Zheng, Y., Dong, L., Liu, N., Luo, X., and He, Z. (2020). Mir-141-3p regulates apoptosis and mitochondrial membrane potential via targeting sirtuin 1 in a 1methyl-4-phenylpyridinium in vitro model of Parkinson's disease. Biomed Res. Int. 2020:7239895. doi: 10.1155/2020/7239895

Zhou, Y., Peng, Y., Liu, M., and Jiang, Y. (2017). MicroRNA-181b inhibits cellular proliferation and invasion of glioma cells via targeting sal-like protein 4. Oncol. Res. 25, 947-957. doi: 10.3727/096504016X14791732531006

Zuo, H., Yuan, J., Chen, Y., Li, S., Su, Z., Wei, E., et al. (2016). A microRNAmediated positive feedback regulatory loop of the NF- $\mathrm{KB}$ pathway in Litopenaeus vannamei. J. Immunol. 196, 3842-3853. doi: 10.4049/jimmunol. 1502358

Zuo, X., Zhou, J., Li, Y., Wu, K., Chen, Z., Luo, Z., et al. (2021). TDP-43 aggregation induced by oxidative stress causes global mitochondrial imbalance in ALS. Nat. Struct. Mol. Biol. 28, 132-142. doi: 10.1038/s41594-020-00537-7

Conflict of Interest: The authors declare that the research was conducted in the absence of any commercial or financial relationships that could be construed as a potential conflict of interest.

Publisher's Note: All claims expressed in this article are solely those of the authors and do not necessarily represent those of their affiliated organizations, or those of the publisher, the editors and the reviewers. Any product that may be evaluated in this article, or claim that may be made by its manufacturer, is not guaranteed or endorsed by the publisher.

Copyright (c) $2022 \mathrm{Chu}$ and Williams. This is an open-access article distributed under the terms of the Creative Commons Attribution License (CC BY). The use, distribution or reproduction in other forums is permitted, provided the original author(s) and the copyright owner(s) are credited and that the original publication in this journal is cited, in accordance with accepted academic practice. No use, distribution or reproduction is permitted which does not comply with these terms. 